\title{
Changes in Alcohol Use During the COVID-19 Pandemic: Impact of the Lockdown Conditions and Mental Health Factors
}

\author{
E. Schmits ${ }^{1}$ (D) F. Glowacz ${ }^{1}$
}

Accepted: 11 November 2020 / Published online: 4 January 2021

(C) Springer Science+Business Media, LLC, part of Springer Nature 2021

\begin{abstract}
The COVID-19 pandemic has led to governments taking a number of restrictive measures. Confinement at home during the COVID-19 crisis could have major implications on mental health and alcohol use behaviors among the whole population. The present study focuses on the role of individual characteristics, contextual factors, and mental health variables on alcohol consumption. A sample of 2871 adults (79\% women) were recruited from the general population through an online self-report questionnaire. Sociodemographic data, lockdown conditions, occupational/physical activity, proximity of contamination, mental health (anxiety, depression, and intolerance of uncertainty), and alcohol consumption (frequency, quantity, and changes) have been assessed. Among participants, $49.1 \%$ of the population reported stable alcohol consumption, $24.5 \%$ reported a decreased in alcohol consumption since the beginning of the lockdown and $26.4 \%$ reported an increase in consumption. Our findings indicate that those individuals who increased their alcohol consumption during the lockdown are often older, working from home, more likely to have children, higher educated, and consume alcohol more frequently and in higher quantities. They also have a greater proximity to contamination and higher levels of anxiety and depression. Our results are discussed in terms of preventive implications.
\end{abstract}

Keywords Alcohol $\cdot$ Lockdown $\cdot$ Homeworking $\cdot$ Anxiety $\cdot$ Depression

\section{E. Schmits}

Emilie.schmits@uliege.be

1 Psychologie Clinique de la Délinquance, Unité de Recherche Adaptation, Résilience et Changement (ARCh), Faculté de Psychologie, Logopédie et Sciences de l'Education (FPLSE), Université de Liège, Liège, Belgium 
The COVID-19 pandemic has led to governments and individuals taking a number of restrictive measures, including lockdowns, social distancing, and voluntary self-isolation (Brooks et al. 2020; Hossain et al. 2020; Huang and Zhao 2020; Sharma et al. 2020). Staying at home during the COVID-19 crisis could have major implications on mental health and substance use behaviors among the whole population. In Belgium, almost $10 \%$ of the population consume alcohol every day and $13 \%$ report problematic alcohol use during their lifetimes. The prevalence of weekly excessive alcohol use and daily consumption is more frequent among men and increases with age. A U-shaped curve is observed for the level of education, i.e., higher alcohol use in the least educated as well as in the most educated individuals. The same is true for risky daily drinking, except for gender (Stévenot and Hogge 2020). Also, parents were less likely to exceed alcohol than non-parents, but were more likely to drink at home (Bowden et al. 2019). Preliminary research on the impact of the COVID-19 pandemic and associated lockdown measures on alcohol use suggests that changes in consumption have taken place during the crisis, but it has not necessarily led to a generalized increase in consumption (Eurotox 2020).

Traumatic, natural, or environmental disasters have often been associated with increases in mental and behavioral disorders such as depression, anxiety, and substance use (Galea et al. 2020). Recent literature has highlighted higher rates of anxiety, depression, sleep disorders, hazardous and harmful alcohol use, and lower mental wellbeing than usual during crises, especially in young people (Ahmed et al. 2020; Brooks et al. 2020; Cao et al. 2020; Glowacz and Schmits 2020; Huang and Zhao 2020; Sharma et al. 2020; Zhang et al. 2020). Variations in physiological stress and poor decision-making abilities increase the risk of stress-induced alcohol consumption (Clay and Parker 2018). We can see these conditions mirrored in the COVID-19 pandemic and subsequent lockdowns throughout the world, where isolation has the potential to lead to alcohol use and misuse in vulnerable individuals (Clay and Parker 2020).

The literature (Rehm et al. 2020) on substance use emphasizes the importance of controlling the evolution of alcohol consumption during a crisis and notes two possible scenarios: an increase in consumption due to distress or a decrease due to the lower accessibility of the substance. Although recommendations have focused on the implications of restrictive measures on substance use disorders - especially the risk of initiation or maintenance of addictive behaviors (Marsden et al. 2020) or complicated alcohol withdrawal (Arya and Gupta 2020; Kar et al. 2020; Teixeira and Testino 2020) among alcohol-dependent persons (Narasimha et al. 2020)-less is known about the changes related to the crisis in recreational and social alcohol use among the general population. The COVID-19 pandemic provides us with a particularly interesting context as the social and recreational spheres have been severely limited due to lockdown measures.

A broad range of crisis-related conditions or mental health vulnerabilities can influence changes in alcohol use, especially because the substance may be used to cope with distress caused by the unusual conditions related to the pandemic. Indeed, the comorbidity between alcohol use and mood or anxiety is frequently explained by self-medication (Turner et al. 2018). Socioeconomic status is also known to be a determinant in alcohol outcomes, especially with greater amounts of alcohol being consumed by individuals with a higher status, while a lower socioeconomic status is associated with more negative consequences (Collins 2016). In the context of pandemic, the whole population is likely to be affected differently depending on the living settings and the psychological conditions.

One of the distressing features of the emerging pandemic is that as long as the precise cause and evolution are unknown, this uncertainty in itself can increase the level of psychosocial 
morbidity (Carleton et al. 2012; Freeston et al. 2020; Mertens et al. 2020; Sankar et al. 2017; Sim and Chua 2004). Intolerance of uncertainty, namely the difficulty of not knowing, is associated with other mental health problems (Glowacz and Schmits 2020, including generalized anxiety disorder (Boswell et al. 2013; Rosser 2019) and depression (Carleton et al. 2012; Gentes and Ruscio 2011). Moreover, intolerance of uncertainty has been shown to be positively correlated with drinking alcohol to cope or conform (Kraemer et al. 2015; Oglesby et al. 2015). Alcohol use may be increased in an attempt to diminish aversive reactivity to ambiguous threats (Gorka et al. 2016).

As suggested at the onset of the outbreak (Pfefferbaum and North 2020), the COVID-19 pandemic has reinforced the importance of monitoring related stressors (e.g., exposition to infection), psychosocial effects (e.g., depression, anxiety, substance use), and indicators or vulnerability (physical or psychological conditions). Therefore, the present study proposes to focus on the role of (1) individual characteristics and contextual factors related to confinement, such as gender, education, living environment, occupational/physical activity and proximity to contamination; and (2) mental health variables including anxiety, depression, and intolerance of uncertainty; on (3) alcohol use, especially frequency, quantity, and perceived changes in consumption during the lockdown.

\section{Methods}

\section{Participants}

A sample of 2871 adults (79\% women) were recruited from the general population through an online self-report questionnaire. Participants were aged between 18 and 85 years $(M=33.67$, $S D=15.35), 84.5 \%$ of them lived in Belgium, $14.8 \%$ in another French-speaking country (mainly France and Canada). Concerning marital status, the distribution is as follows: $17.8 \%$ unmarried without children; $4.1 \%$ unmarried with children; $22 \%$ in a relationship, but not living together; $22 \%$ couples living together without children; $27.9 \%$ couples living together with children; and $6.1 \%$ in another situation. As of the lockdown, $26.2 \%$ were students, $36.5 \%$ were working from home, $12.9 \%$ were working at their place of work, and $24.4 \%$ were taking time off or were out of work. Among the participants, $24.5 \%$ of them had lost some financial income. In the present sample, $12 \%$ thought that they were infected but had not been tested, less than $1 \%$ had tested positive for the coronavirus, and $86.4 \%$ reported that they had not been infected by the coronavirus. Also, $18.3 \%$ believed that one person close to them had been infected but not tested, $12.9 \%$ believed that one person close to them had tested positive, and $68.8 \%$ believed that no close contacts had been contaminated. Finally, $6.9 \%$ of the sample had consulted a psychologist during the lockdown. Participants were not paid for their participation.

\section{Materials and Measures}

Data were obtained through an online self-report questionnaire (approved by the IRB of the University of Liège, Belgium) distributed 1 month after the beginning, in other words just before the end of the lockdown, during the period from April 17 to May 1, 2020. These data are part of a large database collected during lockdown related to the COVID-19 crisis. 


\section{Sociodemographic Data and Lockdown Conditions}

Beyond the usual sociodemographic data (gender, age, country of residence, educational background, and marital status), data on lockdown conditions were also collected, namely regarding the living environment (a score ranging from 1 to 8 evaluating the surface area of the accommodation as well as the availability of a terrace and a garden), professional situation during the lockdown (including four modalities: student, working from home, usual workplace, and no work), and loss of financial income (dichotomous variable: yes/no).

\section{Occupational/Physical Activity and Proximity of Contamination}

Specific data related to the lockdown were also collected. Occupational activity was evaluated through 11 items on a 4-point Likert scale from ( 1 = never; 4 = everyday) evaluating several daily activities such as reading, watching TV, cleaning, or taking care of children. A high score indicates a high frequency of occupational activity $(\alpha=.51 ; M=24.31 ; \mathrm{SD}=4.39 ; \min =11$; $\max =44$ ). Physical activity was also assessed through a continuous variable (number of hours spent doing physical activity) $(M=3.50 ; \mathrm{SD}=4.11 ; \mathrm{Mdn}=3.00 ; \min =0 ; \max =90)$. The primary (oneself) and the secondary (a close person) coronavirus contaminations were specified with three modalities: not infected, infected but not tested, and tested positive for the coronavirus. On this basis, a score of proximity to contamination was determined $(0=$ neither the person himself nor a loved one was infected; $8=$ the person himself and a loved one had tested positive for the coronavirus). A high score indicates a high level of proximity to contamination $(M=.92 ; \mathrm{SD}=1.63 ; \min =0 ; \max =8)$.

\section{Mental Health-Related Variables}

Validated measures were included in the protocol to evaluate mental health-related variables. Each of these scales was adapted to the context of the COVID-19 crisis and the related lockdown. Anxiety and depression were evaluated by the two subscales of the Hospital Anxiety and Depression scale (HAD, Zigmond and Snaith 1983). The HAD is a 14-item scale that proposes seven items related to anxiety $(\alpha=.81 ; M=7.15 ; \mathrm{SD}=4.14 ; \min =0$; $\max =21)$ and seven related to depression $(\alpha=.67 ; M=7.88 ; \mathrm{SD}=3.60 ; \min =0 ; \max =21)$, scoring from 0 to 3. Cut-off points of 8 and 11 have been identified (Bjelland et al. 2002). Two items of the Intolerance of Uncertainty Scale (Freeston et al. 1994) were included to evaluate reactions to uncertain situations, scoring from 1 (not at all corresponding) to 5 (extremely corresponding) $(\alpha=.74 ; M=6.85 ; \mathrm{SD}=2.01 ; \min =2 ; \max =10)$. The two-item ConnorDavidson Resilience Scale (CD-RISC 2) was used (Vaishnavi et al. 2007) to assess resilience $(\alpha=.70 ; M=6.29 ; \mathrm{SD}=1.36 ; \min =0 ; \max =8)$.

\section{Alcohol Use}

Frequency and quantity of alcohol use during the lockdown was assessed through an adapted version of the items of the AUDIT-C questionnaire (Bradley et al. 1998), scoring from 1 (never) to 5 (everyday) for frequency $(M=2.67 ; \mathrm{SD}=1.13 ; \min =1 ; \max =5)$ and from $1(1$ or 2) to 5 (10 or more) for quantity $(M=1.29 ; \mathrm{SD}=0.63 ; \min =1 ; \max =5)$. An additional item was added to evaluate changes in alcohol use during the lockdown by three modalities: decrease, stability, and increase. The context and reasons for alcohol use were evaluated 
through a series of propositions leading to dichotomous responses (yes/no). Participants were asked to specify if, during the lockdown, they used alcohol alone, with a partner, with friends online, or with friends outdoors, and whether they consumed alcohol because they had more time, due to boredom, to virtually spend time with friends, because of stress or to relax, and so on.

\section{Data Analysis}

SPSS 26 software was used to perform descriptive statistics, consistency reliability, Spearman's correlations, chi-square tests (with phi and $V$ coefficients), and Kruskal-Wallis one-way analysis of variance. As group sizes were unequal and the homogeneity of variance is not assumed $(p<.001)$, the nonparametric equivalent of one-way between-group analysis of variance has been conducted to run comparisons. Statistical significance was set at $p<0.05$.

\section{Results}

\section{Descriptive Statistics and Spearman's Correlations}

Among the total sample $(n=2871), 89.7 \%$ of participants had already consumed alcohol during their life $(n=2477)$. Subsequent analyses will only include subjects who had consumed alcohol at least once in their lifetime $(n=2477)$. This subsample includes $79.2 \%$ of women, with an average age of 33.63 years $(\mathrm{SD}=15.02)$. During the lockdown, $49.1 \%$ of participants reported that their alcohol use did not change $(n=1216)$, whereas $24.5 \%$ considered that their use had decreased $(n=608)$ and $26.4 \%$ reported that their consumption had increased during the implementation of restrictive lockdown measures $(n=653)$. Concerning the frequency of alcohol use during the lockdown, 15.4\% never consumed alcohol, 31.4\% once/week or less, $31.2 \%$ 2-4 times/week, $14.3 \%$ almost every day, and $7.7 \%$ every day.

Among participants who consumed alcohol during lockdown $(n=2095), 78.3 \%$ had one or two drinks in a session, $16.7 \%$ three or four, $3.5 \%$ five or six, $0.8 \%$ seven or eight, and $0.7 \%$ ten or more. The context of use was also examined: $69.4 \%$ consumed alcohol with their partner, $54.7 \%$ with friends online, $25.8 \%$ alone, and $8.3 \%$ with friends outdoors (so in defiance of lockdown).

Among alcohol users who believed that their alcohol use had increased during the lockdown $(n=653), 90.6 \%$ explained that they drank alcohol to chill out and relax, $48 \%$ because they had more time than before, $37.4 \%$ to spend time with friends (e.g., on Skype), $32.2 \%$ due to boredom, $30.4 \%$ because they were worried about the pandemic, $16.8 \%$ to be closer to their partner, and $14 \%$ due to tensions with their partners.

Lockdown conditions, physical/occupational activities, alcohol, and mental healthrelated variables were considered. Spearman's correlations among participants who had already consumed alcohol in their lifetimes $(n=2477)$ are shown in Table 1 . The frequency of alcohol use during lockdown was higher in men, significantly and positively correlated to age, educational background, living environment, physical and occupational activities, and quantity of alcohol use, whereas it was negatively correlated to anxiety, depression, and intolerance of uncertainty. The quantity of alcohol use during the lockdown was also higher in men, but only significantly and positively associated to age and proximity of contamination. 
Table 1 Spearman's correlations among the participants who have already used alcohol in their life $(n=2477)$

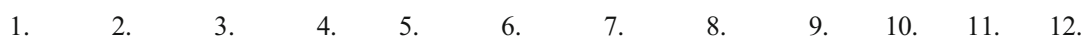

1. Gender 1

2. Age $\quad .03 \quad 1$

3. Educ. $-.06 * * \quad .17 * * \quad 1$

4. Prox. $-.01 \quad .01 \quad .01 \quad 1$

5. Envi. $\quad .04 * \quad .08 * * \quad .01 \quad-.02 \quad 1$

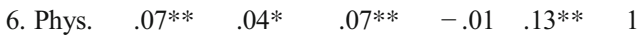

$\begin{array}{lllllll}\text { 7. Occ. }-.05 * * & .22 * * & .15 * * & .02 & .09 * * & .10 * * & 1\end{array}$

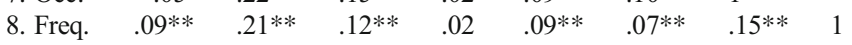

$\begin{array}{lllllllllll}\text { 9. Quan. } & .12 * * & .04 * & .02 & .09 * * & -.01 & .01 & .01 & .23 * * & 1\end{array}$

10. Anx. $-.14 * *-.16 * *-.08 * * .05 * *-.08 * *-.07 * *-.06 * *-.08 * * \quad .01 \quad 1$

11. Dep. $-.05 *-.09 * *-.11 * * \quad .01-.11 * *-.16 * *-.18 * *-.06 * * \quad .02 \quad .53 * * 1$

12. Unc. $-.19 * *-.15 * *-.13 * * \quad .01-09^{*}-.08^{* *}-.10 * *-.11 * *-.09 * *-.03 \quad .52 * * \quad .39 * * 1$

Educ. educational background, Prox. proximity to contamination, Envi. living environment, Phys. physical activity, Occ. occupational activity, Freq. frequency of alcohol use during lockdown, Quan. quantity of alcohol use during lockdown, Anx. anxiety, Dep. depression, Unc. intolerance of uncertainty. Concerning quantity of alcohol use, correlations are carried out among participants who have used alcohol during lockdown $(n=$ 2095).*p<.05. **p $<.001$

\section{Changes in Alcohol Use-Chi-Square Tests}

Characteristics including gender, professional conditions, loss of income, and having children have been compared between the three groups (decreased use, stable use, increased use). They significantly differ based on profession during lockdown $\left(X^{2}=194.43 ; p=<.001 ; V=.20\right)$ and whether participants were living with children or not $\left(X^{2}=178.04 ; p=<.001 ; V=.26\right)$. In fact, students were likely to decrease their alcohol use (respectively $46 \%, 23 \%$, and $14.1 \%$ ) whereas individuals working from home tended to increase their alcohol consumption during lockdown (respectively $27.7 \%, 36.4 \%$, and $49.9 \%$ ). Those who increased their alcohol use were more likely to have children (respectively $21.4 \%, 49.8 \%$, and $55.7 \%$ ). No difference was found for gender $\left(X^{2}=1.20 ; p=.54 ; V=.02\right)$ and loss of income $\left(X^{2}=2.47 ; p=.29 ; V=.03\right)$.

\section{Changes in Alcohol Use-Kruskal-Wallis Test}

As group sizes were unequal and the homogeneity of variance is not assumed $(p<.001)$, the nonparametric equivalent of one-way between-group analysis of variance was conducted to compare the three groups (decreased use, stable use, increased use). The results of the KruskalWallis $H$ test are shown in Table 2.

With the exception of living environment and physical activity, all variables significantly differed according to the user group. Bonferroni post hoc analyses reveal that users who increased their alcohol consumption during lockdown were older, had a higher level of education, and consumed alcohol more frequently and in higher quantity than those who decreased or maintained pre-lockdown levels of alcohol consumption. Also, those who increased their alcohol consumption also experienced a greater proximity to contamination and higher levels of anxiety and depression than those who maintained their alcohol use (but not compared to people who decreased alcohol use). Similarly, participants who decreased alcohol use during the lockdown reported a greater proximity to contamination, as well as more anxiety, depression, and intolerance of uncertainty than people who maintained their 
Table 2 Kruskal-Wallis one-way analysis of variance between the three groups $(n=2477)$

\begin{tabular}{|c|c|c|c|c|c|c|}
\hline & $\begin{array}{l}(1) \\
\text { Decreased } \\
\text { alcohol use } \\
n=608 \\
m(\mathrm{SD})\end{array}$ & $\begin{array}{l}(2) \\
\text { Stable } \\
\text { alcohol use } \\
n=1216 \\
m(\mathrm{SD})\end{array}$ & $\begin{array}{l}(3) \\
\text { Increased } \\
\text { alcohol use } \\
n=653 \\
m \text { (SD) }\end{array}$ & $H(\mathrm{dl})$ & Sig. & $\begin{array}{l}\text { Comparisons Sig. } \\
\text { diff. between groups }\end{array}$ \\
\hline Age & $28.92(13.10)$ & $34.84(15.93)$ & 35.77 (13.99) & 89.78 (2) & $<.001$ & $1-2 ; 1-3 ; 2-3$ \\
\hline Education & $5.29(1.01)$ & $5.47(0.92)$ & $5.59(0.84)$ & $34.01(2)$ & $<.001$ & $1-2 ; 1-3 ; 2-3$ \\
\hline Prox. to cont. & $0.97(1.60)$ & $0.85(1.60)$ & $1.03(1.72)$ & $10.56(2)$ & .005 & $1-2 ; 2-3$ \\
\hline Environ. & $5.31(1.90)$ & $5.44(1.82)$ & $5.57(1.77)$ & $4.62(2)$ & .09 & N/A \\
\hline Phys. Act. & 3.77 (3.58) & $3.42(3.66)$ & $3.72(4.97)$ & $5.67(2)$ & .06 & N/A \\
\hline Occup Act. & $22.93(4.10)$ & $24.66(4.30)$ & $25.10(4.35)$ & $99.73(2)$ & $<.001$ & $1-2 ; 1-3$ \\
\hline Freq. of alc. & $2.02(0.83)$ & $2.48(1.05)$ & $3.64(0.85)$ & $743.62(2)$ & $<.001$ & $1-2 ; 1-3 ; 2-3$ \\
\hline Quant. of alc. & $1.26(0.65)$ & $1.22(0.55)$ & $1.41(0.71)$ & $51.25(2)$ & $<.001$ & $1-3 ; 2-3$ \\
\hline Anxiety & $7.48(4.20)$ & $6.73(3.94)$ & $7.40(4.25)$ & $15.93(2)$ & $<.001$ & $1-2 ; 2-3$ \\
\hline Depression & $8.15(3.45)$ & $7.51(3.48)$ & $8.13(3.76)$ & $19.13(2)$ & $<.001$ & $1-2 ; 2-3$ \\
\hline Uncertainty & 7.03 (1.97) & $6.71(2.01)$ & $6.89(2.01)$ & $11.51(2)$ & .003 & $1-2$ \\
\hline
\end{tabular}

Comparisons Sig. diff. between groups multiple comparisons. This column shows the significant differences between groups $(p<.05)$, using the Bonferroni correction. Prox. to cont. proximity to contamination, Environ. living environment, Phys. Act. physical activity, Occup. Act. occupational activity, Freq. of alc. frequency of alcohol use, Quant. of alc. quantity of alcohol use

alcohol use. No significant differences were found concerning the living environment and physical activity.

\section{Discussion}

The COVID-19 pandemic, which has necessitated drastic measures to limit the spread of virus, has imposed abrupt, often dramatic changes to individuals' professional, social, and family lives as well as interrupting a range of leisure activities (Brooks et al. 2020; Hossain et al. 2020; Huang and Zhao 2020; Sharma et al. 2020). The impact of containment measures on health and mental health is a real concern, and studies tend to confirm a rise in psychological distress, anxiety, and depression in the general population, especially among the young (Ahmed et al. 2020; Brooks et al. 2020; Cao et al. 2020; Glowacz and Schmits 2020 ; Huang and Zhao 2020; Sharma et al. 2020; Zhang et al. 2020). Although risks in relation to substance use have been reported (e.g., Marsden et al. 2020; Pfefferbaum and North 2020; Rehm et al. 2020), few studies to date are available. The objectives of our study, based on an online survey conducted within the community during the lockdown, are to assess drinking behaviors and perceived changes in alcohol use behaviors, as well as the factors associated with these. Specifically, the present study aims to assess the impact of COVID-19-related stressors, such as sociodemographic data, lockdown conditions, and mental health, on alcohol outcomes (frequency, quantity, and changes) among the general population.

\section{Alcohol Use Frequency, Quantity, and Correlates in the General Population}

This research demonstrates that half of the population maintained their usual drinking habits, whereas one quarter decreased and one quarter increased their alcohol use. As suggested by the preliminary results of recent unpublished research (Eurotox 2020), changes in 
consumption have taken place during the crisis, but the pandemic has not necessarily caused a generalized increase in consumption. However, just about $21 \%$ of the sample reported that they used alcohol every day or almost, which is higher than usual rates of daily use $(10 \%)$ within the Belgian population (Stévenot and Hogge 2020). The current situation may have therefore increased the occurrence of alcohol use. In agreement with epidemiologic data collected before the pandemic (Stévenot and Hogge 2020), the frequency of use is higher in men. According to this study's results, people drank mostly in couples or with friends online, and the main reasons given for the increase in alcohol consumption were relaxation and having more time than before. These observations highlight the role of couple context in the use of alcohol (Foulstone et al. 2016) and people's need/desire to bridge social distance and maintain social interaction through digital technologies (Galea et al. 2020; Merchant and Lurie 2020) in this period of isolation. Also, one can assume that the relationship to time has been altered during the containment period, especially the time spent at home. Stress, boredom, and gaps within the usual daily routine could increase the risk of stress-induced alcohol consumption.

For the entire sample, alcohol may also have an anxiolytic effect, particularly in relation to the proximity of the disease (contamination of oneself or one's relatives) which generates anxiety in the whole population, even if women are generally more likely to drink to regulate negative affect and stress reactivity (Peltier et al. 2019). Globally, the more a person consumes alcohol, the less anxious or depressed symptoms he or she experiences. In fact, considering the stress-inducing effect of the pandemic, as with other traumatic or environmental disasters (Galea et al. 2020), and the self-medication hypothesis (Turner et al. 2018), alcohol use and misuse can occur to reduce the unpleasant feelings related to the COVID-19 pandemic, especially isolation (Clay and Parker 2020). In our sample, anxiety is also correlated with the context of confinement such as the available space in the residence, with people in confined spaces and without outdoor space being more anxious and depressive. However, being physically active and having a variety of occupations other than work reduces anxiety. According to De Ridder (2016), the majority of adults (18 to 64 years of age) meet the WHO physical activity recommendations ( 2 h 30 min per week of moderate-intensity physical activity). Previous research highlighted that physical activity was related to better mental health during the lockdown (Pieh et al. 2020). Nevertheless, physical and occupational activities, associated with less anxiety and depression, are associated with more frequent alcohol use, underlining the special role of alcohol in the culture of sport (Munro 2000). Favorable socioeconomic indicators, such as education and home space/comfort, also increase the frequency of alcohol use (Collins 2016).

Moreover, intolerance of uncertainty, which is highly correlated with depression (Carleton et al. 2012; Gentes and Ruscio 2011) and anxiety (Boswell et al. 2013; Rosser 2019), is also associated with the frequency of alcohol use. However, in contrast to studies which suggest that intolerance of uncertainty is likely to be positively correlated with drinking alcohol to cope or conform (Kraemer et al. 2015; Oglesby et al. 2015) or to diminish aversive reactivity to ambiguous threats (Gorka et al. 2016), our results show that the frequency of use is negatively correlated with intolerance of uncertainty. We proffer two explanations for this divergence: alcohol consumption helps people to tolerate uncertainty (as an extension of the anxiolytic effect); people who are intolerant of uncertainty will be more cautious and less inclined to use a psychoactive substance (precautionary principle). It is also worthwhile noting that the frequency of use seems to be more significant than the quantity of alcohol use in the context of the current crisis. 


\section{Alcohol Use Changes and Focus on Increasing Consumption}

In this present study, individuals who reported increased alcohol use (one quarter of the population) during the lockdown were both men and women and they were more likely to have children. Even if the pandemic has caused changes in alcohol consumption habits in both men and women, it is well known that women are more vulnerable to anxiety and depression, which could have an impact on alcohol use. The people who reported an increase in alcohol use were older and higher educated, as suggested by authors (Collins 2016) who noted that the amounts of alcohol consumed were greater in individuals with higher socioeconomic status. A recent systematic review (Probst et al. 2020) specified that the association between alcohol consumption and socioeconomic status (SES) is complex and that global drinking patterns have to be taken into account, rather than just the average quantity of alcohol consumed. People who increased their alcohol use were also busier during lockdown, and more of them were working from home. This can be explained by an existing alcohol use patterns among a particular category of workers at their workplace (Nielsen et al. 2018). In other words, consumption may have shifted from a work setting to home (maybe a more educated and at-risk population), especially if individuals turn to alcohol use in order to reduce tension in a period of elevated work-related stress and fatigue (Frone 2016). Also, working from home could have led to increased use because of the absence of workplace regulations and availability of the substance at home (Pidd et al. 2016). Those who increased their consumption alcohol are also those who have children. These can be considered as stressors in the context of confinement and working from home. Literature highlighted that individuals who became parents as emerging adults showed role-related decline in alcohol consumption (Little et al. 2009) and that, even if parents are less likely to exceed alcohol than non-parents, they are more likely to drink at home (Bowden et al. 2019). Surprisingly, loss of income was not defined as a relevant indicator of changes in alcohol use, perhaps because it does not constitute a worry for this particular group.

The frequency and quantity of use was higher in this subsample of individuals who perceived an increase in their alcohol consumption during the pandemic. Globally, the reported frequency of alcohol use was higher than usual epidemiologic data (Stévenot and Hogge 2020). Previous literature (Rehm et al. 2020) had anticipated this scenario of increases and decreases in consumption due to distress related to the crisis. Our results highlight that a change in usual consumption (increase or decrease) is associated with more anxiety and depression (in comparison with those who maintain their usual use). Anxious and depressed persons are susceptible to changes to their habits, not especially in favor of an increase, which is consistent with other preliminary studies (Eurotox 2020). On the other hand, in contrast with other research (Kraemer et al. 2015; Oglesby et al. 2015), intolerance of uncertainty (often associated with depression and anxiety) was more present in people who reduced their consumption. This is convergent with our precautionary hypothesis (people who are intolerant to uncertainty will be more cautious and inclined to reduce their use).

\section{Conclusion, Implications, and Limitations}

In summary, the COVID-19 and subsequent lockdowns has seen half of the population change their drinking patterns, either by increasing or decreasing the amount of alcohol they drink. The rates of daily use in the community have increased during the pandemic. In many cases, this is due to individuals consuming alcohol with partners in their home, with friends, and with family over social networks or using the substance as a way to relax during this stressful period. In this 
context, older men with a higher education and benefiting from better living conditions consumed alcohol more frequently. Concerning changes in use habits during the pandemic, individual working from home and parents were particularly vulnerable to a perceived increase of alcohol use. Anxious and depressed persons would be susceptible to changes to their habits, increasing or decreasing their consumption. However, people who frequently used alcohol seemed less affected by anxiety and depressive symptoms supporting the self-medication hypothesis. This research has several clinical implications, such as the quick implementation of alcohol prevention strategies in the context of health crises, paying particular attention to individuals working from home, and focusing on their reasons and motivations in this specific stress-induced alcohol use context.

However, despite relevant findings and obvious strengths (such as a large population and diversity of variables), our study has some limitations. The use of self-reported questionnaires leads to well-known biases, such as self-representational biases, introspective limits, or social desirability (Nisbett and Wilson 1977; Schwarz 1999). Additional assessment methods should be considered, such as qualitative methods. It is based on an online survey, not a clinical population with addiction disorders. It is evident that people suffering from alcohol use disorder, characterized by an array of mental, physical, and behavioral symptoms, belong to a marginalized community and are invariably more prone to contract infection during the COVID-19 pandemic (Columb et al. 2020; Ornell et al. 2020). This population should be included in future research. Also, as the sample is over-represented by women, subsequent studies should aim to reach more male participants.

\section{Compliance with Ethical Standards}

Conflict of Interest The authors declare that they have no competing interests.

Ethical Approval All respondents agreed to participate in the study, which was approved by the ethics committee at Liege University.

\section{References}

Ahmed, M. Z., Ahmed, O., Aibao, Z., Hanbin, S., Siyu, L., \& Ahmad, A. (2020). Epidemic of COVID-19 in China and associated psychological problems. Asian Journal of Psychiatry, 51, 102092. https://doi.org/10. 1016/j.ajp.2020.102092.

Arya, S., \& Gupta, R. (2020). COVID-19 outbreak: challenges for addiction services in India. Asian Journal of Psychiatry, 51(April), 102086. https://doi.org/10.1016/j.ajp.2020.102086.

Bjelland, I., Dahl, A. A., Haug, T. T., \& Neckelmann, D. (2002). The validity of the Hospital Anxiety and Depression Scale. Journal of Psychosomatic Research, 52(2), 69-77. https://doi.org/10.1016/s00223999(01)00296-3.

Boswell, J. F., Thompson-hollands, J., Farchione, T. J., \& Barlow, D. H. (2013). Intolerance of uncertainty: a common factor in the treatment of emotional disorders., 69(6), 630-645. https://doi.org/10.1002/jclp.21965.

Bowden, J., Delfabbro, P., Room, R., Miller, C., \& Wilson, C. (2019). Parental drinking in Australia: does the age of children in the home matter? Drug and Alcohol Review, 38, 306-315.

Bradley, K. A., McDonell, M. B., Bush, K., Kivlahan, D. R., Diehr, P., \& Fihn, S. D. (1998). The AUDIT alcohol consumption questions. Alcoholism: Clinical \& Experimental Research, 22(8), 1842. https://doi.org/ 10.1097/00000374-199811000-00034.

Brooks, S. K., Webster, R. K., Smith, L. E., Woodland, L., Wessely, S., Greenberg, N., \& Rubin, G. J. (2020). Rapid Review The psychological impact of quarantine and how to reduce it: rapid review of the evidence. The Lancet, 395(10227), 912-920. https://doi.org/10.1016/S0140-6736(20)30460-8.

Cao, W., Fang, Z., Hou, G., Han, M., Xu, X., Dong, J., \& Zheng, J. (2020). The psychological impact of the COVID-19 epidemic on college students in China. Psychiatry Research, 287, 112934. https://doi.org/10. 1016/j.psychres.2020.112934. 
Carleton, R. N., Mulvogue, M. K., Thibodeau, M. A., McCabe, R. E., Antony, M. M., \& Asmundson, G. J. G. (2012). Increasingly certain about uncertainty: intolerance of uncertainty across anxiety and depression. Journal of Anxiety Disorders, 26(3), 468-479. https://doi.org/10.1016/j.janxdis.2012.01.011.

Clay, J. M., \& Parker, M. O. (2018). The role of stress-reactivity, stress-recovery and risky decision-making in psychosocial stress-induced alcohol consumption in social drinkers. Psychopharmacology, 235(11), 32433257. https://doi.org/10.1007/s00213-018-5027-0.

Clay, J. M., \& Parker, M. O. (2020). Alcohol use and misuse during the COVID-19 pandemic: a potential public health crisis? The Lancet Public Health, 5(5), e259. https://doi.org/10.1016/S2468-2667(20)30088-8.

Collins, S. (2016). Associations between socioeconomic factors and alcohol outcomes. Alcohol Research, 38(1), 83-94.

Columb, D., Hussain, R., \& Gara, C. (2020). Addiction psychiatry and COVID-19: impact on patients and service provision. Irish Journal of Psychological Medicine, 1-5. https://doi.org/10.1017/ipm.2020.47.

De Ridder, K. (2016). Rapport 3: Activité physique et sédentarité. Résumé des principaux résultats. In T. Lebacq \& E. Teppers (Eds.), Enquête de consommation alimentaire 2014-2015. Bruxelles: WIV-ISP.

Eurotox. (2020). Quel est l'impact du confinement sur la consommation de drogues et d'alcool? https://eurotox. org/2020/05/26/enquetes-sur-limpact-du-confinement-sur-la-consommation-dalcool-et-de-drogues/. Accessed 3 July 2020.

Foulstone, A. R., Kelly, A. B., Kifle, T., Baxter, J., Foulstone, A. R., Kelly, A. B., Kifle, T., \& Baxter, J. (2016). Heavy alcohol use in the couple context: a nationally representative longitudinal study. Substance Use \& Misuse, 51(11), 1441-1450. https://doi.org/10.1080/10826084.2016.1178295.

Freeston, M. H., Rhéaume, J., Letarte, H., Dugas, M. J., \& Ladouceur, R. (1994). Why do people worry? Personality and Individual Differences, 17(6), 791-802. https://doi.org/10.1016/0191-8869(94)90048-5.

Freeston, M., Tiplady, A., Mawn, L., Bottesi, G., \& Thwaites, S. (2020). Towards a model of uncertainty distress in the context of coronavirus (Covid-19). Cogn Behav Therap, 13, e31. https://doi.org/10.31234/osf.io/v8q6m.

Frone, M. (2016). Work stress and alcohol use: developing and testing a biphasic self-medication model selfmedication model. Work \& Stress, 8373, 374-394. https://doi.org/10.1080/02678373.2016.1252971.

Galea, S., Merchant, R. M., \& Lurie, N. (2020). The mental health consequences of COVID-19 and physical distancing. JAMA Internal Medicine., 180, 817-818. https://doi.org/10.1001/jamainternmed.2020.1562.

Gentes, E. L., \& Ruscio, A. M. (2011). Clinical Psychology Review A meta-analysis of the relation of intolerance of uncertainty to symptoms of generalized anxiety disorder, major depressive disorder, and obsessive-compulsive disorder. Clinical Psychology Review, 31(6), 923-933. https://doi.org/10.1016/j.cpr.2011.05.001.

Glowacz, F., Schmits, E. (2020) Psychological distress during the COVID-19 lockdown: The young adults most at risk. Psychiatry Research, 293, 113486.

Gorka, S. M., Lieberman, L., Phan, K. L., \& Shankman, S. A. (2016). Association between problematic alcohol use and reactivity to uncertain threat in two independent samples. Drug and Alcohol Dependence, 164, 8996. https://doi.org/10.1016/j.drugalcdep.2016.04.034.

Hossain, M., Sultana, A., \& Purohit, N. (2020). Mental health outcomes of quarantine and isolation for infection prevention: a systematic umbrella review of the global evidence. Epidemiology Health. https://doi.org/10. 4178/epih.e2020038.

Huang, Y., \& Zhao, N. (2020). Generalized anxiety disorder, depressive symptoms and sleep quality during COVID-19 outbreak in China: a web-based cross-sectional survey. Psychiatry Research, 288, 112954. https://doi.org/10.1016/j.psychres.2020.112954.

Kar, S. K., Arafat, S. M. Y., Sharma, P., Dixit, A., Marthoenis, M., \& Kabir, R. (2020). COVID-19 pandemic and addiction: current problems and future concerns. Asian Journal of Psychiatry, 51, 102064. https://doi. org/10.1016/j.ajp.2020.102064.

Kraemer, K. M., Mcleish, A. C., \& Bryan, E. M. O. (2015). Addictive Behaviors The role of intolerance of uncertainty in terms of alcohol use motives among college students. Addictive Behaviors, 42, 162-166. https://doi.org/10.1016/j.addbeh.2014.11.033.

Little, M., Handley, E., Leuthe, E., \& Chassin, L. (2009). The impact of parenthood on alcohol consumption trajectories: variations as a function of timing of parenthood, familial alcoholism, and gender. Development and Psychopathology, 21(2), 661-682. https://doi.org/10.1017/S0954579409000352.

Marsden, J., Darke, S., Hall, W., Hickman, M., Holmes, J., Humphreys, K., Neale, J., Tucker, J., \& West, R. (2020). Mitigating and learning from the impact of COVID-19 infection on addictive disorders. Addiction, 115(6), 1007-1010. https://doi.org/10.1111/add.15080.

Merchant, R. M., \& Lurie, N. (2020). Social media and emergency preparedness in response to novel coronavirus. JAMA, 323(20), 2011-2012. https://doi.org/10.1001/jama.2020.4469.

Mertens, G., Gerritsen, L., Duijndam, S., Salemink, E., \& Engelhard, I. (2020). Fear of the coronavirus (COVID19): predictors in an online study conducted in March 2020. Available at: Psyarxiv.Com/2p57j. https://doi. org/10.31234/osf.io/2p57j.

Munro, G. (2000). Challenging the culture of sport and alcohol. International Journal of Drug Policy, 11, 199-202. 
Narasimha, V. L., Shukla, L., Mukherjee, D., Menon, J., Huddar, S., Panda, U. K., Mahadevan, J., Kandasamy, A., Chand, P. K., Benegal, V., \& Murthy, P. (2020). Complicated alcohol withdrawal-an unintended consequence of COVID-19 lockdown. Alcohol and Alcoholism, 1-4. https://doi.org/10.1093/alcalc/agaa042.

Nielsen, M. B., Gjerstad, J., \& Frone, M. (2018). Alcohol use among Norwegian workers: associations with health and well-being. Occup Med (Lond), 68, 96-98. https://doi.org/10.1093/occmed/kqy014.

Nisbett, R. E., \& Wilson, T. D. (1977). Telling more than we can know: verbal reports on mental processes. Psychological Review, 84, 231-259.

Oglesby, M., Albanese, B., Chavarria, J., \& Schmidt, N. B. (2015). Intolerance of uncertainty in relation to motives for alcohol use. Cognitive Therapy and Research, 39, 356-365. https://doi.org/10.1007/s10608014-9665-1.

Ornell, F., Moura, H., Scherer, J., Pechansky, F., Kessler, F., \& von Diemen, L. (2020). The COVID-19 pandemic and its impact on substance use: implications for prevention and treatment. Psychiatry Research, 289, 113096. https://doi.org/10.1016/j.psychres.2020.113096.

Peltier, M. R., Verplaetse, T. L., Mineur, Y. S., Petrakis, I. L., Cosgrove, K. P., Picciotto, M. R., \& Mckee, S. A. (2019). Neurobiology of stress sex differences in stress-related alcohol use. Neurobiology of Stress, 10, 100149. https://doi.org/10.1016/j.ynstr.2019.100149.

Pfefferbaum, B., \& North, C. (2020). Mental health and the COVID-19 pandemic. New England Journal of Medicine, 382(21), 1978-1979. https://doi.org/10.1056/NEJMp2008017.

Pidd, K., Kostadinov, V., \& Roche, A. (2016). Do workplace policies work? An examination of the relationship between alcohol and other drug policies and workers' substance use. International Journal of Drug Policy, 28, 48-54. https://doi.org/10.1016/j.drugpo.2015.08.017.

Pieh, C., Budimir, S., \& Probst, T. (2020). The effect of age, gender, income, work, and physical activity on mental health during coronavirus disease (COVID-19) lockdown in Austria. Journal of Psychosomatic Research, 136, 110186. https://doi.org/10.1016/j.jpsychores.2020.110186.

Probst, C., Kilian, C., Sanchez, S., Lange, S., \& Rehm, J. (2020). The role of alcohol use and drinking patterns in socioeconomic inequalities in mortality: a systematic review. The Lancet Public Health, 5(6), E234-E332.

Rehm, J., Kilian, C., Ferreira-Borges, C., Jernigan, D., Monteiro, M., Parry, C. D. H., Sanchez, Z. M., \& Manthey, J. (2020). Alcohol use in times of the COVID-19: implications for monitoring and policy. Drug and Alcohol Review, 39(4), 301-304. https://doi.org/10.1111/dar.13074.

Rosser, B. A. (2019). Intolerance of uncertainty as a transdiagnostic mechanism of psychological difficulties: a systematic review of evidence pertaining to causality and temporal precedence. Cognitive Therapy and Research, 43(2), 438-463. https://doi.org/10.1007/s10608-018-9964-z.

Sankar, R., Robinson, L., Honey, E., \& Freeston, M. (2017). 'We know intolerance of uncertainty is a transdiagnostic factor but we don't know what it looks like in everyday life': a systematic review of intolerance of uncertainty behaviours. Clinical Psychology Forum, 296, 10-15.

Schwarz, N. (1999). Self-reports: how the questions shape the answers. American Psychologist, 54, $93-105$.

Sharma, V., Reina Ortiz, M., \& Sharma, N. (2020). Risk and protective factors for adolescent and young adult mental health within the context of COVID-19: a perspective from Nepal. Journal of Adolescent Health, 67, 3-5. https://doi.org/10.1016/j.jadohealth.2020.04.006.

Sim, K., \& Chua, H. C. (2004). The psychological impact of SARS: a matter of heart and mind., 170(5), 811-812.

Stévenot, C., \& Hogge, M. (2020). Tableau de bord de l'usage de drogues et ses conséquences socio-sanitaires en Wallonie. Belgique: Eurotox.

Teixeira, J. A., \& Testino, G. (2020). Risks of alcohol abuse, alcoholism and stress-related drinking during the COVID-19 pandemic. 1-4. https://doi.org/10.5114/ain.2020.95762.

Turner, S., Mota, N., Bolton, J., \& Sareen, J. (2018). Self-medication with alcohol or drugs for mood and anxiety disorders: a narrative review of the epidemiological literature. Depression and Anxiety, 35, 851-860. https:// doi.org/10.1002/da.22771.

Vaishnavi, S., Connor, K., \& Davidson, J. R. T. (2007). An abbreviated version of the Connor-Davidson Resilience Scale (CD-RISC), the CD-RISC2: psychometric properties and applications in psychopharmacological trials. Psychiatry Research, 152(2-3), 293-297. https://doi.org/10.1016/j.psychres.2007.01.006.

Zhang, S. X., Wang, Y., Rauch, A., \& Wei, F. (2020). Unprecedented disruption of lives and work: health, distress and life satisfaction of working adults in China one month into the COVID-19 outbreak. Psychiatry Research, 288, 112958. https://doi.org/10.1016/j.psychres.2020.112958.

Zigmond, A. S., \& Snaith, R. P. (1983). The Hospital Anxiety and Depression Scale. In Acta Psychiatrica Scandinavica (Vol. 67, Issue 6, pp. 361-370). Blackwell Publishing. https://doi.org/10.1111/j.1600-0447. 1983.tb09716.x.

Publisher's Note Springer Nature remains neutral with regard to jurisdictional claims in published maps and institutional affiliations. 